\title{
Diagnostic Value of Cardiac Magnetic Resonance Strain Analysis for Detection of Cardiac Sarcoidosis
}

\section{Diagnostischer Wert der MRT-Strain-Bildgebung zur Beurteilung einer kardialen Sarkoidose}

Authors

Darius Dabir ${ }^{1}$, David Meyer ${ }^{1}$, Daniel Kuetting ${ }^{1}$, Julian Luetkens ${ }^{1}$, Rami Homsi ${ }^{1}$, Carmen Pizarro², Jennifer Nadal ${ }^{3}$, Daniel Thomas ${ }^{1}$

Affiliations

1 Radiology, University of Bonn, Germany

2 Medicine II, Cardiology, Pneumology, and Angiology, University of Bonn, Germany

3 Medical Biometry, University of Bonn, Germany

Key words

cardiac, sarcoidosis, strain, feature-tracking

received 21.12.2017

accepted 11.03.2018

Bibliography

DOI https://doi.org/10.1055/a-0598-5099

Published online: 2018

Fortschr Röntgenstr 2018; 190: 712-721

(c) Georg Thieme Verlag KG, Stuttgart · New York

ISSN 1438-9029

Correspondence

Dr. Daniel Thomas

Radiologische Universitätsklinik, Universität Bonn,

Sigmund-Freud-Strasse 25, 53127 Bonn, Germany

Tel.: ++49/2 28/2871 1122

Fax: ++49/2 28/28715598

Daniel.Thomas@ukb.uni-bonn.de

\section{ZUSAMMENFASSUNG}

Ziel Ziel dieser Studie war es, die diagnostische Wertigkeit der MRT-basierten Strain-Analyse zum Nachweis einer kardialen Beteiligung bei Patienten mit systemischer Sarkoidose zu ermitteln. Darüber hinaus wurden die Strainwerte mit Standard MRT-Parametern (Ödem/T2-ratio, relatives enhancement, late gadolinium enhancement) bezüglich des Outcomes verglichen.

Material und Methoden 61 Patienten mit bioptisch gesicherter extrakardialer Sarkoidose wurden mittels Herz-MRT untersucht. Entsprechend der MRT-Ergebnisse wurden die Patienten in 2 Gruppen unterteilt: Patienten mit (CMR+; n=23) und ohne (CMR-; $n=38$ ) sarkoidosetypische Veränderungen des Herzens. Als Kontrollgruppe dienten 22 altersgematchte Herzgesunde. Linksventrikuläre Funktionsparameter sowie longitudinaler und zirkumferentieller Strain wurden in allen drei Gruppen gemessen.

Ergebnisse Sarkoidosepatienten wiesen im Vergleich zu Herzgesunden einen signifikant eingeschränkten longitudinalen Strain (GLS) auf, während keine signifikanten Unterschiede zwischen den beiden Patientengruppen festgestellt werden konnten. CMR+ Patienten wiesen im Vergleich zu CMR- Patienten und Herzgesunden signifikant eingeschränkte zirkumferentielle Strainwerte auf. Zwischen CMR- Patienten und Herzgesunden konnten keine signifikanten Unterschiede bezüglich zirkumferentiellem Strain festgestellt werden. Patienten mit negativem Outcome wiesen im Vergleich zu Herzgesunden einen signifikant niedrigeren GLS auf. Darüber hinaus war der GLS in Patienten mit negativem Outcome auch gegenüber den übrigen $\mathrm{CMR}+$ und CMR- Patienten eingeschränkt, jedoch ohne statistische Signifikanz zu erreichen.

Schlussfolgerung GLS ist der einzige Strainparameter, der einen signifikanten Unterschied zwischen Sarkoidosepatienten mit ansonsten unauffälligem MRT (CMR-) und Herzgesunden aufweist und darüber hinaus bei Patienten mit negativem Outcome eingeschränkt ist. Folglich könnte GLS als potentieller Indikator für eine frühe kardiale Beteiligung dienen.

\section{Kernaussagen}

- GLS ist bei Sarkoidosepatienten mit ansonsten unauffälligem Herz-MRT signifikant eingeschränkt im Vergleich zu Herzgesunden

- GLS ist bei Patienten mit negativem Outcome eingeschränkt

- GLS könnte als potentieller Indikator für eine frühe kardiale Beteiligung dienen

\section{ABSTRACT}

Purpose The aim of this study was to investigate the diagnostic value of cardiac magnetic resonance (CMR)-derived strain parameters in patients with sarcoidosis, and to compare results to standard CMR markers of sarcoidosis (edema/T2 ratio, early gadolinium enhancement, late gadolinium enhancement) for prediction of disease outcome.

Materials and Methods 61 patients with biopsy-proven sarcoidosis underwent CMR examination. According to CMR 
results, patients were divided into two different groups: patients with $(C M R+; n=23)$ and without $(C M R-; n=38)$ findings consistent with cardiac sarcoidosis. In addition, a group of healthy age-matched volunteers (controls; $n=22$ ) served as controls. Left ventricular functional parameters as well as left ventricular longitudinal and circumferential strain were evaluated in all three groups.

Results Compared to controls, global longitudinal strain (GLS) was significantly impaired in patients with sarcoidosis, irrespective of cardiac involvement. No significant differences in GLS could be revealed between CMR+ and CMR- patients. Circumferential strain parameters were significantly impaired in CMR+ patients in comparison to CMR- patients and controls, while no significant differences could be revealed between CMR- patients and controls. GLS was significantly lower in patients with a negative outcome compared to controls. Compared to the rest of the CMR+ and CMR- patients, the GLS in patients with a negative outcome was further reduced but did not reach statistical significance.
Conclusion GLS is the only strain parameter detecting left ventricular functional impairment in sarcoidosis patients with otherwise unsuspicious CMR and controls. GLS is further reduced in patients with a negative outcome. Thus, GLS may have the potential to serve as a marker for early cardiac involvement in sarcoidosis.

\section{Key points}

- GLS is significantly impaired in sarcoidosis patients with an otherwise inconspicuous CMR, compared to controls

- GLS is reduced in patients with a negative outcome

- GLS may serve as a marker for early cardiac involvement in sarcoidosis

\section{Citation Format}

- Dabir D, Meyer D, Kuetting D et al. Diagnostic Value of Cardiac Magnetic Resonance Strain Analysis for Detection of Cardiac Sarcoidosis. Fortschr Röntgenstr 2018; 190: 712721

\section{Background}

Sarcoidosis is a systemic inflammatory disease characterized by non-caseating granulomas. The prevalence in the United States and Europe is as high as 10-40/100 000 [1]. Most commonly the lungs are affected ( $90 \%$ ). However, up to $30 \%$ of patients may show extrapulmonary manifestations [2].

Cardiac involvement of sarcoidosis is a life-threatening condition and is associated with a 60-75\% 5-year survival rate [3]. Although only $5 \%$ of patients with cardiac involvement have clinically apparent symptoms, which include conduction disturbances, ventricular tachycardia, or sudden cardiac death, autopsy studies revealed a much higher prevalence $(20-60 \%)[4,5]$.

Cardiac magnetic resonance (CMR) imaging and ${ }^{18}$ fluoro-desoxy-glucose positron-emission tomography ( $\left.{ }^{18} \mathrm{FDG}-\mathrm{PET}\right)$, which have reported sensitivities of $75 \%$ and $88 \%$, have emerged as the preferred non-invasive imaging techniques for the detection of cardiac involvement [6]. However, even these imaging techniques can only detect advanced stages of cardiac sarcoidosis when edema or fibrotic changes within the myocardium are present.

In contrast, echocardiography-based strain studies have shown that left ventricular contractility is already impaired in otherwise asymptomatic sarcoidosis patients [4]. CMR strain imaging is a reliable technique to quantitatively assess left ventricular (LV) systolic and diastolic function. Thus, the aim of this study was first to investigate left ventricular global systolic as well as diastolic CMR strain parameters in sarcoidosis patients with CMR-based diagnosis of cardiac sarcoidosis and to compare these to the results of CMR-negative sarcoidosis patients and controls. Second, we aimed to investigate how CMR strain parameters relate to outcome.

\section{Methods}

\section{Study protocol}

Between 02/2010 and 06/2015, 61 patients (age range: 24 to 79 years; median: 52.9 years) with biopsy-proven sarcoidosis were included in the study. The vast majority presented with pulmonary manifestation $(90.2 \%)$. The study population consisted of outpatients receiving treatment at the local department of pneumology and patients recruited from a nationwide sarcoidosis support group (Sarkoidose-Netzwerk e. V.). Except for patients with a history of arterial hypertension, none of the patients included in this study had a history of significant cardiac disease (e.g. myocardial infarction, myocarditis, cardiomyopathy). Patients' characteristics are listed in table 2.

Patients underwent CMR comprising a routine clinical imaging protocol for the assessment of inflammatory cardiac disease. Cardiac involvement of sarcoidosis was diagnosed if at least one of the following pathologies was present: increased left ventricular early gadolinium enhancement ratio $(E G E r \geq 4)$, increased myocardial signal on T2-weighted images (T2-ratio $\geq 2$ ), detection of at least one myocardial lesion with non-ischemic late gadolinium enhancement (LGE) pattern.

According to CMR results, patients were categorized into 2 different groups: patients with cardiac involvement according to CMR (CMR+) and patients without CMR signs of cardiac involvement (CMR-). In addition, an age-matched group of healthy volunteers served as controls.

Patients underwent clinical follow-up (median follow-up time: 48.2 months) to assess outcome. A negative outcome was defined as death, heart failure-related hospitalization, cardiac device implantation, or arrhythmias. 


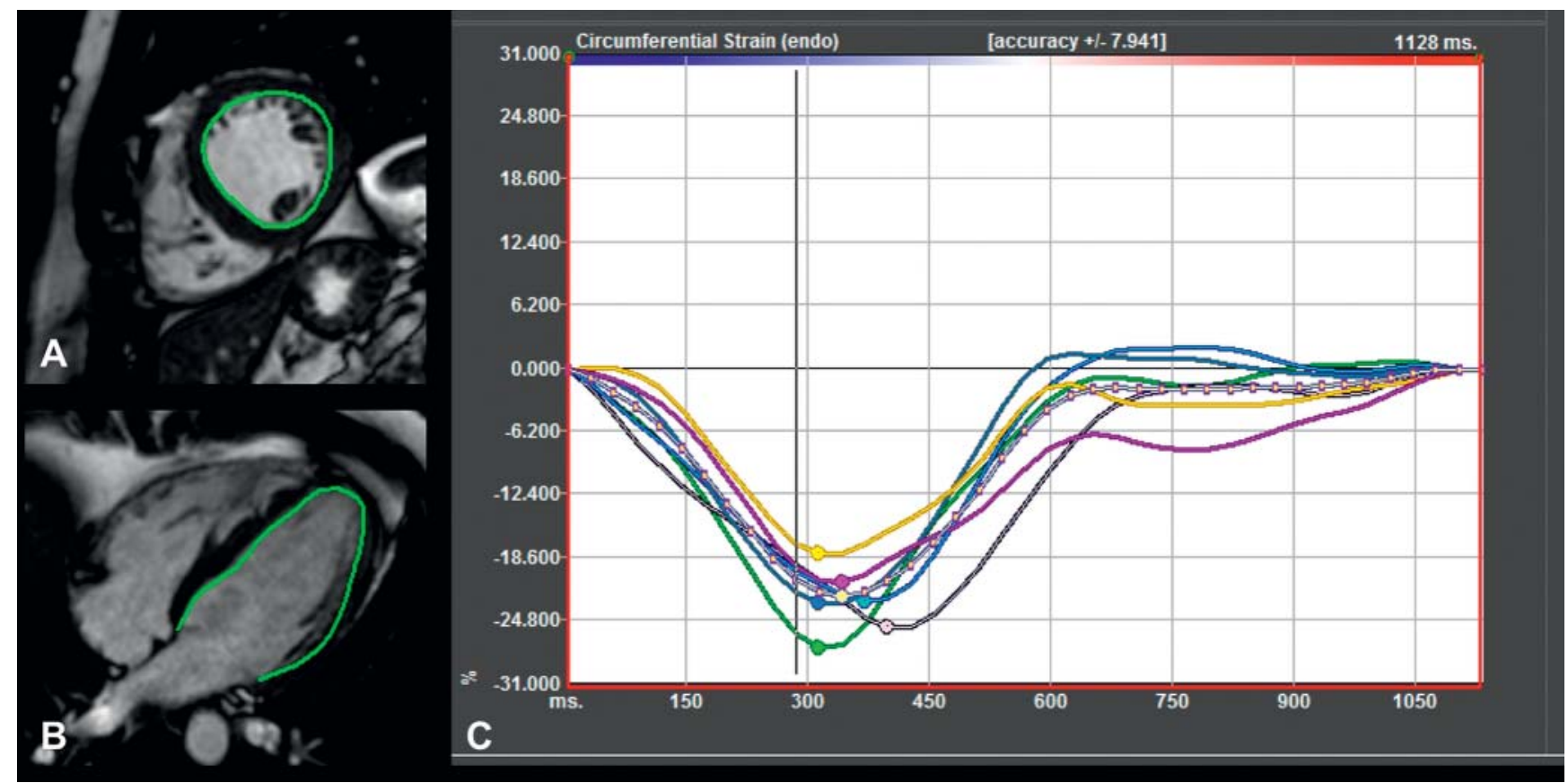

- Fig. 1 CMR-FT assessment in a healthy control subject. Endocardial borders are being drawn in Cine images of a midventricular SA A and HLA B view and subsequently automatically propagated through the whole heart cycle. Image $\mathbf{C}$ gives an example of the resulting circumferential strain curves (segmental strain and mean (dotted)).

- Abb. 1 MRT-FT-Analyse bei einem herzgesunden Individuum. Die endokardialen Konturen werden in der Funktionsbildgebung in der mittventrikulären kurzen Herzachse $\mathbf{A}$ und der horizontalen langen Herzachse $\mathbf{B}$ eingezeichnet und im Folgenden über den gesamten Herzzyklus automatisch verfolgt. Bild C zeigt die resultierenden Strainkurven (segmentaler Strain und Mittelwert (gepunktet)).

\section{Cardiac MR Imaging}

Patients underwent CMR at 1.5 T (Intera, Philips Healthcare, Best, The Netherlands) using a 5-channel surface coil for signal reception. For the assessment of left ventricular (LV) functional analysis, electrocardiographically (ECG)-gated balanced steady-state free precession cine images were acquired in breath hold in the horizontal long axis (HLA), the vertical long axis (VLA), the left ventricular outflow tract (LVOT), and the short axis (SA), the latter comprising the whole left ventricle using 12 slices.

For the appraisal of myocardial edema, black-blood T2-weighted short tau inversion recovery sequences were acquired in SA, VLA, and transverse orientation.

For the assessment of inflammation-associated myocardial hyperemia, transverse free-breathing $\mathrm{T} 1$-weighted images were acquired prior to and $<1 \mathrm{~min}$ after injection of a single dose ( $0.1 \mathrm{mmol}$ per kilogram of bodyweight) of extracellular contrast agent (Gadovist, Bayer Healthcare, Leverkusen, Germany), as previously described [7]. Immediately after image acquisition, a second single dose of contrast agent was administered for the assessment of myocardial fibrosis and scar tissue using the late gadolinium enhancement (LGE) technique. LGE images were acquired 10-15 min after the administration of the second contrast agent bolus using segmented inversion-recovery gradient echo sequences in HLA, SA, and VLA. Image acquisition was performed according to the updated Society of Cardiac Magnetic Resonance recommendations [8].

\section{Image analysis}

Cardiac function (LV ejection fraction (LVEF), left ventricular enddiastolic volume (LVEDV), and interventricular septal thickness (IVST)) was determined offline, using dedicated software (ViewForum, Philips Healthcare). LVEF and LVEDV were measured manually by tracing the endocardial borders including papillary muscles in the left ventricular volume. Quantitative assessment of LGE relative to LV mass was performed using the " $n$-standard deviation method" as previously described [9]. Using this method, a region of interest is placed within the remote myocardium to detect the mean signal intensity $(\mathrm{SI})$ of the myocardium. Voxels with a signal intensity 4 standard deviations above the mean SI are defined as areas of LGE.

\section{Feature Tracking Analysis}

CMR feature tracking (CMR-FT) was performed using dedicated software (Diogenes; TomTec; Germany). The left ventricular circumferential strain was measured in midventricular short axis orientation, whereas the longitudinal strain was measured from the HLA. The LV endocardial borders were outlined by manually drawing a contour. The software then calculated the LV strain by automatically tracking myocardial voxels throughout the whole heart cycle using the FT algorithm as previously described [10]. The collected data was then used to plot global strain curves as well as strain rate curves ( $\mathbf{F i g} \mathbf{1}, \mathbf{2}$ ). The peak systolic strain rate (PSSR), peak diastolic strain rate (PDSR), peak systolic circumferential strain (PSECC), and early diastolic strain rate (EDSR) were 

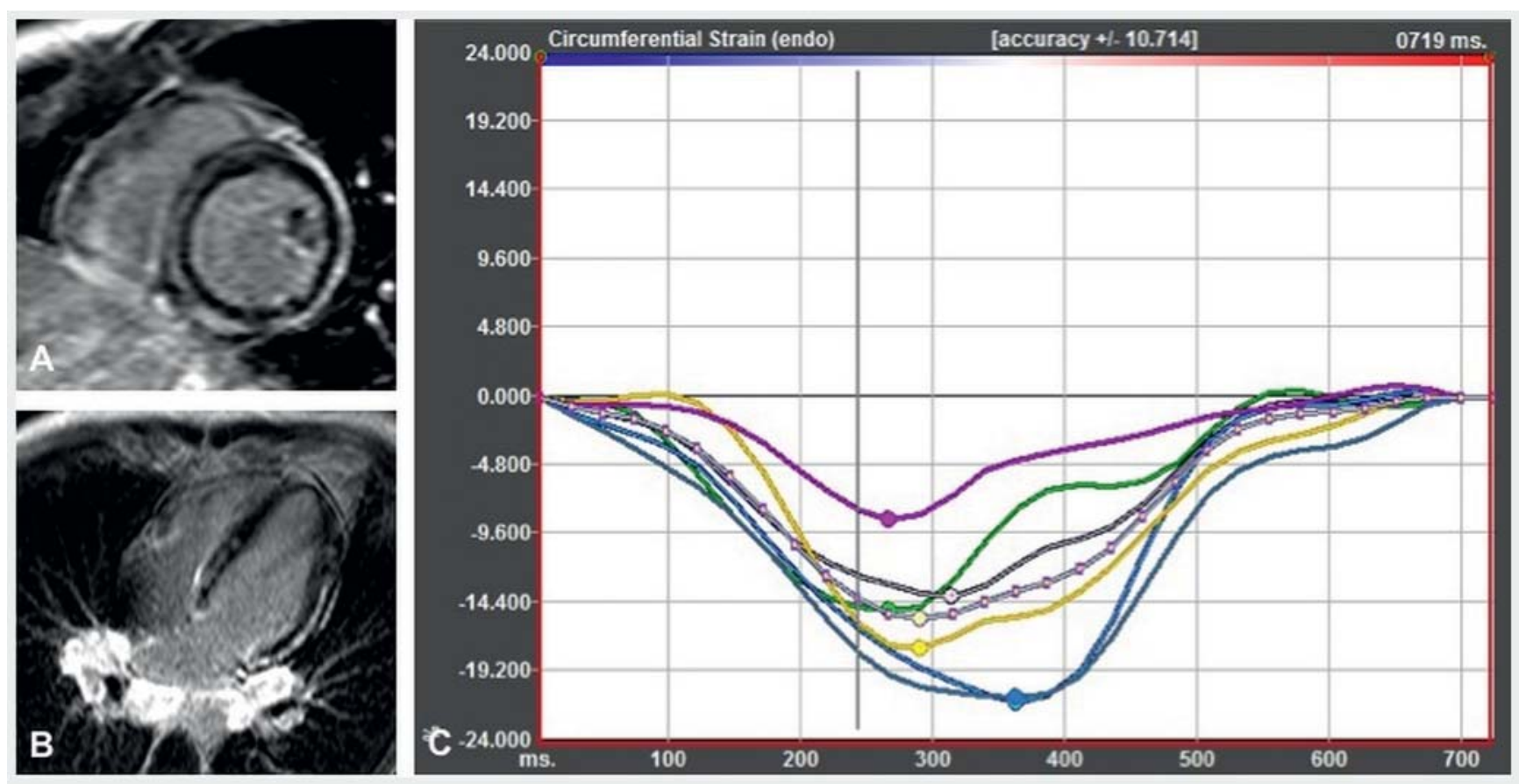

- Fig. 2 35-year-old patient with cardiac sarcoidosis. A+B Late enhancement images in midventricular SA A and HLA B views with circumferential midmyocardial and subepicardial LGE. Image $\mathbf{C}$ shows corresponding strain curves which show decreased and asynchronous strain compared to the example of a healthy subject in $>$ Fig. $1 C$.

- Abb. 2 35-jährige Patientin mit kardialer Sarkoidose. A+B Vitalitätsbildgebung in kurzer A und horizontaler langer Achse B mit Nachweis zirkumferenter mittmyokardial und subepikardial gelegenen Kontrastmittelanreicherungen. Bild $\mathbf{C}$ zeigt die korrespondierenden Strainkurven, welche sich im Vergleich zu einem gesunden Individuum (Abb. 1C) deutlich eingeschränkt und asynchron darstellen.

calculated from the mid-ventricular SA slice, whereas the global longitudinal strain (GLS) was derived from the HLA. Peak strain rates were derived from the minimum and maximum value of the strain rate curve, while the end-diastolic strain rate (EDSR) corresponded to the incline from end-systole to mid-diastole [11].

\section{Statistical analysis}

SPSS software version 25 (SPSS Inc., Chicago, IL, USA) was used for statistical analysis. Data are represented using means \pm standard deviations (SD) for continuous variables and frequency distributions with percentages for categorical variables.

Mean differences between groups were compared using univariate ANOVA by applying Turkey-HSD post-hoc tests. Differences in frequencies were examined with the exact Fisher test. A p-value $<0.05$ was considered significant.

\section{Results}

Within the CMR+ group, 16 patients $(70 \%)$ showed LGE ( $\triangleright$ Fig. 3 ). On average, LGE accounted for $6 \%$ of left ventricular mass (1 $36 \%$ ). 10 of these 16 patients (44\%) presented with isolated LGE. In 4 cases (17\%) LGE was associated with edema, and 2 patients (9\%) presented with additional edema and increased EGEr. 7 patients (30\%) presented with increased EGEr alone ( $\triangleright$ Table 1 ).

None of the CMR- patients presented with LGE, edema, or increased relative enhancement.
- Table 1 Prevalence of pathologies occurring within the CMR+ group.

- Tab. 1 Häufigkeit von Pathologien in der CMR+ Gruppe.

\begin{tabular}{|l|l|}
\hline Pathology & $\mathbf{n}=$ \\
\hline LGE & $10(43 \%)$ \\
\hline LGE + edema & $4(17 \%)$ \\
\hline LGE + edema + EGEr & $2(9 \%)$ \\
\hline EGEr & $7(30 \%)$ \\
\hline
\end{tabular}

The LVEDV, LVEF, and IVST were within normal range in all three groups. Intergroup comparison showed no significant difference in LVEF or LVEDV. The IVST of CMR+ patients was significantly higher compared to CMR- patients ( $\bullet$ Table 2 ).

GLS was significantly restricted in patients with sarcoidosis (CMR+ and CMR-) compared to healthy controls, while no significant differences in GLS could be revealed between CMR+ and CMR- patients ( $\triangleright$ Fig. 4). PSSR, PDSR, PSECC and EDSR were significantly decreased in CMR+ patients in comparison to CMRpatients and controls, while no significant differences could be revealed between CMR- patients and controls ( $\triangleright$ Fig. 5 , - Table 3). 

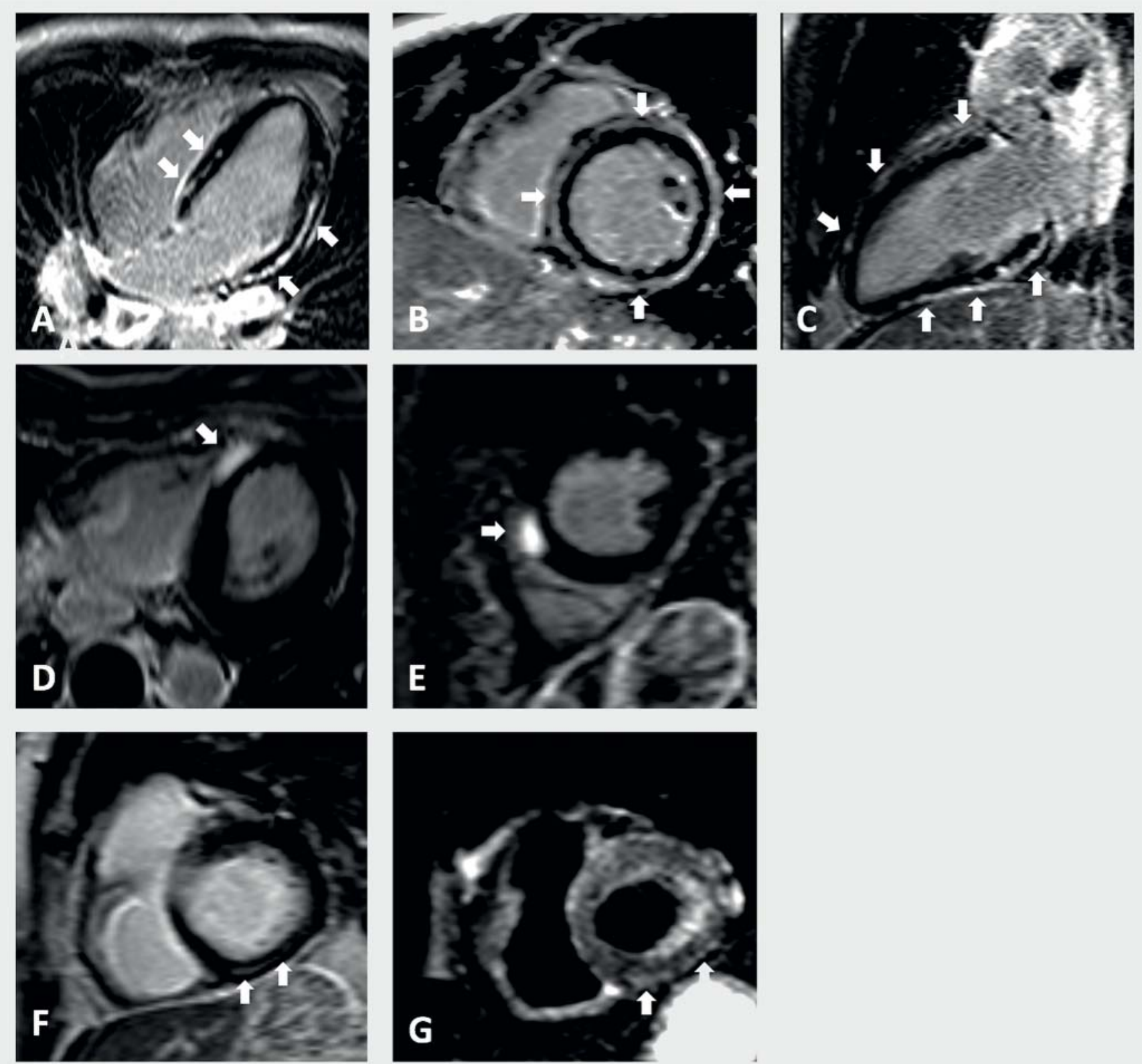

- Fig. 3 Examples of pathological CMR findings (white arrows). A-C 35-year-old patient with circumferential subepicardial and midmyocardial LGE in HLA A, SA B und VLA C views. D+E 64-year-old patient with subepicardial and midmyocardial LGE within the apical septal wall in transverse $\mathbf{D}$ and SA E views. F+G SA views of a 64-year-old patient with dull, midmyocardiall striatal LGE $\mathbf{F}$ within the basal inferior and infero-septal wall with corresponding edema in the $\mathrm{T} 2$ black blood image $\mathbf{G}$.

- Abb. 3 Beispiele für sarkoidosetypische Veränderungen (weiße Pfeile). A-C 35-jähriger Patient mit zirkumferentiellem subepikardialem und mittmyokardialem LGE, dargestellt in der HLA A, SA B und VLA C. D+E 64-jähriger Patient mit subepikardialem und mittmyokardialem LGE apikal septal, dargestellt in HLA D und SA E. F+G 64-jähriger Patient mit mittmyokardialem flauem, streifigem LGE F basal inferior und infero-septal sowie assoziiertem Ödem in der T2 black blood Sequenz, jeweils dargestellt in der SA.

The median follow-up was 48.2 months. Three CMR+ patients (13\%) had a negative outcome with one patient undergoing pacemaker implantation due to a combination of AV-block III and left bundle branch block, a second patient developed ventricular extrasystoles (VES) and a third patient developed cardiac insufficiency. GLS was significantly lower in patients with a negative outcome (median $-15.8 \%$ ) compared to controls (median $-21.1 \%$; $p<0.05)$. Compared to the remaining sarcoidosis patients (median $-18.5 \%$ ), GLS in patients with a negative outcome was further reduced but did not reach statistical significance. 
- Table 2 Clinical characteristics of patients and controls.

- Tab.2 Klinische Eigenschaften der Patienten und Herzgesunden.

\begin{tabular}{|c|c|c|c|c|c|}
\hline & All patients with sarcoidosis & CMR + & CMR - & Controls & Significance \\
\hline $\mathbf{N}$ & 61 & 23 & 38 & 22 & \\
\hline Age (years) & $52.7 \pm 12$ & $52.6 \pm 10$ & $52.7 \pm 12$ & $59.3 \pm 17$ & 0.137 \\
\hline Male & $33(54 \%)$ & $13(57 \%)$ & $20(53 \%)$ & $12(55 \%)$ & 0.957 \\
\hline \multicolumn{6}{|c|}{ Left ventricular functional parameters } \\
\hline LVEDV (ml) & $116.5 \pm 28$ & $114.9 \pm 24$ & $117.5 \pm 31$ & $136 \pm 39$ & 0.051 \\
\hline LVEF (\%) & $64.5 \pm 8$ & $63.8 \pm 9$ & $64.9 \pm 5$ & $63.8 \pm 9$ & 0.196 \\
\hline IVST (mm) & $10.7 \pm 1.7$ & $10.7 \pm 1.6$ & $9.5 \pm 1.7$ & $9.7 \pm 1.9$ & 0.044 \\
\hline \multicolumn{6}{|c|}{ Cardiovascular risk factors } \\
\hline Diabetes & 7 (11\%) & $4(17 \%)$ & $3(8 \%)$ & & \\
\hline Hypertension & $13(21 \%)$ & $7(30 \%)$ & $6(16 \%)$ & & \\
\hline Smoking & $8(13 \%)$ & $3(13 \%)$ & $5(13 \%)$ & & \\
\hline Hyperlipidemia & $7(11 \%)$ & $3(13 \%)$ & $4(11 \%)$ & & \\
\hline Obesity & $6(10 \%)$ & $3(13 \%)$ & $3(8 \%)$ & & \\
\hline \multicolumn{6}{|l|}{ Symptoms } \\
\hline Angina & $3(5 \%)$ & $1(4 \%)$ & $2(5 \%)$ & & \\
\hline Dyspnea (NYHA $\geq I I)$ & $9(15 \%)$ & $2(9 \%)$ & $7(18 \%)$ & & \\
\hline Fatigue & $6(10 \%)$ & $1(4 \%)$ & $5(13 \%)$ & & \\
\hline \multicolumn{6}{|l|}{ ECG abnormality } \\
\hline VES & $1(2 \%)$ & $1(4 \%)$ & 0 & & \\
\hline RBBB & $2(3 \%)$ & $1(4 \%)$ & $1(3 \%)$ & & \\
\hline Trifascicular block & $1(2 \%)$ & $1(4 \%)$ & 0 & & \\
\hline $\mathrm{AF}$ & $1(2 \%)$ & 0 & $1(3 \%)$ & & \\
\hline \multicolumn{6}{|c|}{ Sarcoidosis manifestations } \\
\hline $\begin{array}{l}\text { Primary pulmonary } \\
\text { manifestation }\end{array}$ & $55(90 \%)$ & $20(87 \%)$ & 35 (92\%) & & \\
\hline Lymph node & $6(10 \%)$ & $3(13 \%)$ & $3(8 \%)$ & & \\
\hline Liver & $7(11 \%)$ & $3(13 \%)$ & $4(11 \%)$ & & \\
\hline Skin & 7 (11\%) & $3(13 \%)$ & $4(11 \%)$ & & \\
\hline Spleen & $2(3 \%)$ & 0 & $2(5 \%)$ & & \\
\hline Bone & $3(5 \%)$ & $1(4 \%)$ & $2(5 \%)$ & & \\
\hline Eye & $5(8 \%)$ & $1(4 \%)$ & $4(11 \%)$ & & \\
\hline \multicolumn{6}{|l|}{ Years since diagnosis } \\
\hline$<1$ & $26(43 \%)$ & $13(57 \%)$ & $13(34 \%)$ & & \\
\hline $1-4$ & $20(33 \%)$ & $10(43 \%)$ & $10(26 \%)$ & & \\
\hline $5-9$ & $4(7 \%)$ & 0 & $4(11 \%)$ & & \\
\hline$\geq 10$ & $11(18 \%)$ & 0 & $11(29 \%)$ & & \\
\hline \multicolumn{6}{|l|}{ Laboratory results } \\
\hline slL2 R (U/ml) & $752(30-2039)$ & $725(378-1510)$ & $769(30-2039)$ & & \\
\hline NT pro-BNP (pg/ml) & $68(8-322)$ & $59(12-156)$ & $77(8-322)$ & & \\
\hline Trop I (ng/ml) & 0 & 0 & 0 & & \\
\hline \multicolumn{6}{|l|}{ Medication } \\
\hline B-blockers & $13(21 \%)$ & $6(26 \%)$ & $7(18 \%)$ & & \\
\hline
\end{tabular}


- Table 2 (Continuation)

\begin{tabular}{|l|l|l|l|l|}
\hline & All patients with sarcoidosis & CMR + & CMR - & Controls \\
\hline ARB & $7(11 \%)$ & $3(13 \%)$ & $4(11 \%)$ \\
\hline ASS & $3(5 \%)$ & $2(9 \%)$ & $1(3 \%)$ & $2(5 \%)$ \\
\hline CCB & $4(7 \%)$ & $2(9 \%)$ & $3(8 \%)$ \\
\hline Statins & $4(7 \%)$ & $1(4 \%)$ & $1(3 \%)$ \\
\hline Diuretics & $3(5 \%)$ & $2(9 \%)$ & $24(63 \%)$ & $13(34 \%)$ \\
\hline $\begin{array}{l}\text { Steroids n) } \\
\text { Baseline }\end{array}$ & $37(61 \%)$ & $13(57 \%)$ & $15(65 \%)$ & $2(5 \%)$ \\
\hline Follow-up & $28(46 \%)$ & 0 & & \\
\hline Azathioprine & $2(3 \%)$ & & \\
\hline
\end{tabular}

\section{Discussion}

Cardiac sarcoidosis is associated with a poor prognosis. Thus, early diagnosis of cardiac involvement is warranted for timely treatment. Clinical manifestations of cardiac sarcoidosis include conduction disturbances (mostly atrioventricular conduction block), ventricular tachycardia, heart failure, or sudden cardiac death.

Diagnosis of cardiac sarcoidosis is currently based on the revised 2006 Japanese Ministry of Health and Welfare (JMHW) guidelines. These guidelines require either histologic or clinical confirmation, with certain major and minor criteria needing to be fulfilled for the latter [2]. Due to a mainly focal or patchy distribution of inflammatory lesions, myocardial biopsies are often associated with false-negative results. Although ECG and echocardiography represent the currently implemented clinical screening modalities, they are associated with a low sensitivity (50\% and $25 \%$, respectively) [12]. CMR and ${ }^{18}$ FDG-PET have much higher sensitivities with $75 \%$ and $88 \%$ [6]. However, these imaging modalities only allow for detection of cardiac sarcoidosis at advanced stages of disease, when edematous or fibrotic changes of the myocardium are already present.

A diagnostic marker which enables early detection of cardiac involvement and thus timely treatment has not yet been established.

Strain imaging allows for accurate measurement of left ventricular myocardial deformation and function. Furthermore, studies have revealed that strain not only detects myocardial dysfunction prior to ejection fraction changes, but is also predictive for outcome regarding cardiomyopathy and heart failure [13 - 15].

Recent echocardiography studies, evaluating the diagnostic value of strain measurements in patients with sarcoidosis, revealed promising results for disease detection [4, 16-18]. In agreement with these studies, patients in the current study had a normal LVEF and a normal LVEDV. While IVST differed significantly between CMR+ and CMR- patients, it was in the normal range in all groups, rendering an association with cardiac involvement unlikely.

Similar to the results of Orii et al., who investigated longitudinal, radial, and circumferential echo strain in 45 patients with and without late gadolinium enhancement in CMR, circumferential

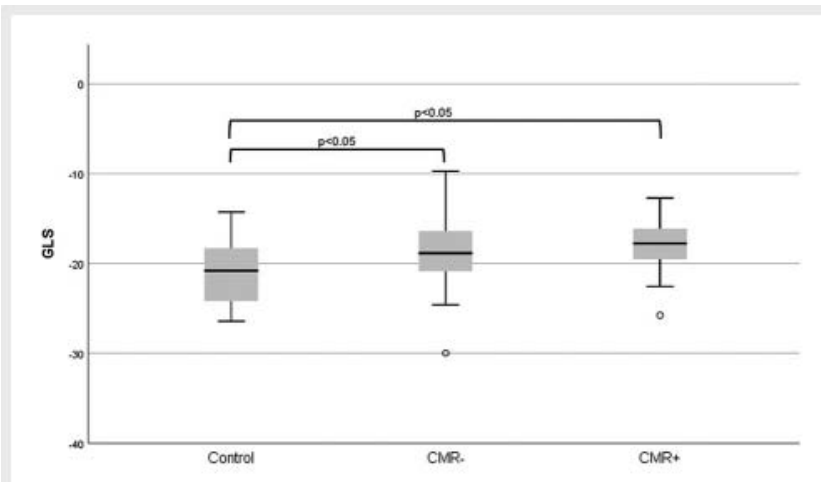

- Fig. 4 Box plot showing GLS in healthy controls, CMR- and CMR+ patients.

- Abb. 4 Boxplotdarstellung des GLS von herzgesunden Individuen, CMR- und CMR+ Patienten.

strain parameters in the underlying study population were significantly impaired in CMR+ patients compared to CMR- patients and controls. These findings underline the ability of circumferential strain to discriminate between healthy and diseased myocardium, but only in stages of disease, where inflammatory processes within the myocardium are already visible by conventional CMR (edema, LGE; $>$ Fig. 5). Tigen et al. also found significant differences in global circumferential strain between patients and controls. However, information regarding cardiac inflammation was lacking in this study [16].

Comparable to circumferential strain, GLS has been shown to be impaired in LGE+ patients compared to LGE- patients. Interestingly, in one study a significant reduction of GLS was detected in sarcoidosis patients in whom cardiac sarcoidosis was ruled out by other clinical criteria (JMHW 2006) [4]. Similarly, in the underlying study, GLS was not only impaired in CMR+ patients, but also in CMR-sarcoidosis patients ( $\triangleright$ Fig. 4 ).

This finding might be explained as follows: First, longitudinal strain mainly derives from the subendocardial layer. Thus, GLS impairment might be attributed to early diffuse interstitial changes within the myocardium involving the subendocardial layer which 


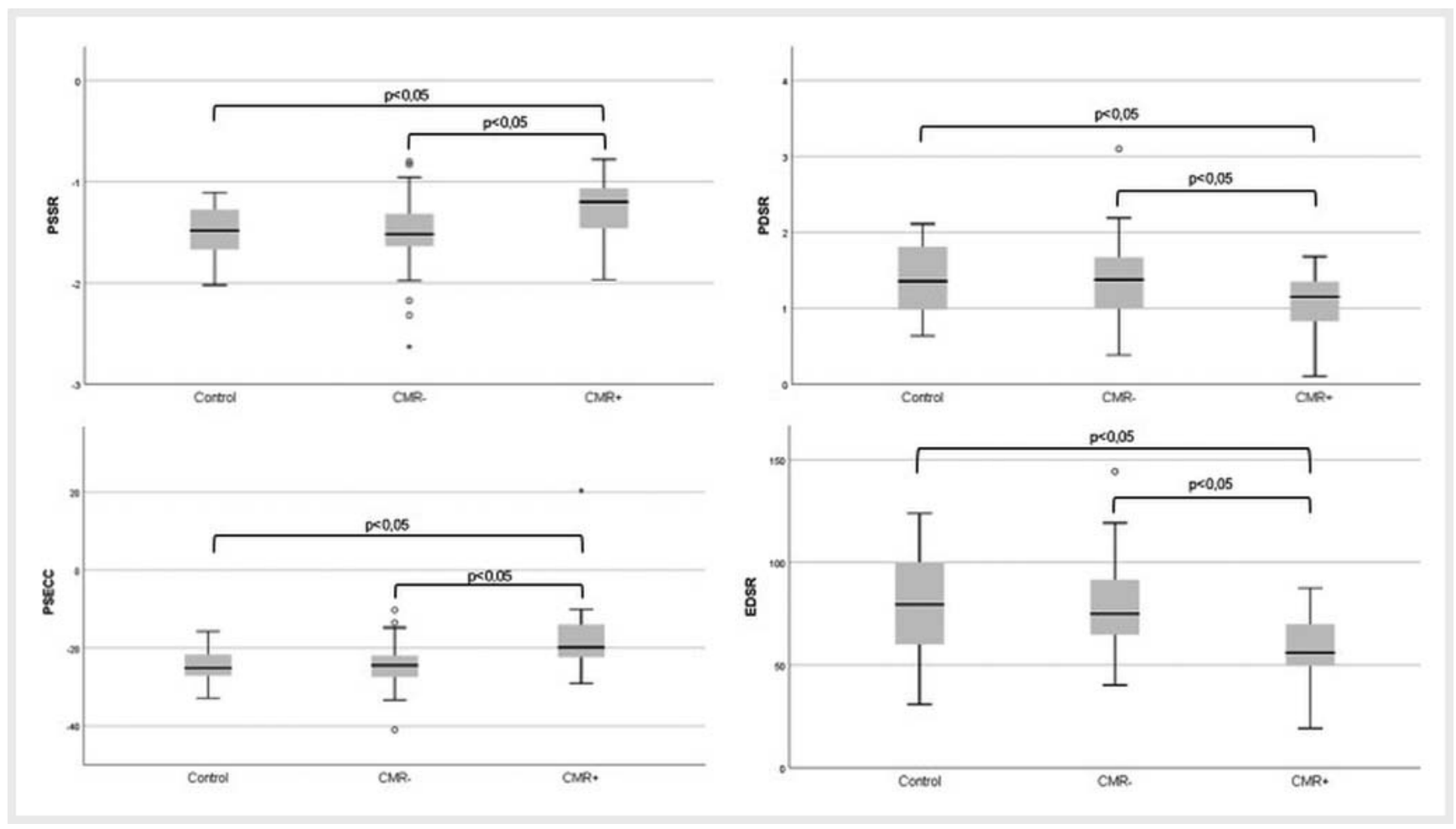

- Fig. 5 Box plot showing PSSR A, PDSR B, PSECC C, and EDSR D in healthy controls, CMR- and CMR+ patients.

- Abb. 5 Boxplotdarstellung der PSSR A, PDSR B, PSECC C und EDSR D von herzgesunden Individuen, CMR- und CMR+ Patienten.

- Table 3 Analysis of variance (ANOVA) results between groups revealing significant differences regarding all investigated strain parameters.

- Tab. 3 Ergebnisse der Varianzanalyse (ANOVA) zwischen den Gruppen mit signifikanten Unterschieden bzgl. aller untersuchten Strainparameter.

\begin{tabular}{|c|c|c|c|c|}
\hline & Group & Number & & Significance \\
\hline \multirow[t]{3}{*}{ GLS (\%) } & CMR- & 38 & $-18.6 \pm 3.9$ & \multirow[t]{3}{*}{0.007} \\
\hline & Controls & 22 & $-21.1 \pm 3.4$ & \\
\hline & CMR+ & 23 & $-17.9 \pm 3$ & \\
\hline \multirow[t]{3}{*}{$\operatorname{PSSR}\left(\mathrm{s}^{-1}\right)$} & CMR- & 38 & $-1.5 \pm 0.4$ & \multirow[t]{3}{*}{0.011} \\
\hline & Controls & 22 & $-1.5 \pm 0.3$ & \\
\hline & $\mathrm{CMR}^{+}$ & 23 & $-1.3 \pm 0.3$ & \\
\hline \multirow[t]{3}{*}{$\operatorname{PDSR}\left(\mathrm{s}^{-1}\right)$} & CMR- & 38 & $1.4 \pm 0.5$ & \multirow[t]{3}{*}{0.032} \\
\hline & Controls & 22 & $1.4 \pm 0.5$ & \\
\hline & CMR+ & 23 & $1.1 \pm 0.4$ & \\
\hline \multirow[t]{3}{*}{ PSECC (\%) } & CMR- & 38 & $-24.3 \pm 5.6$ & \multirow[t]{3}{*}{$<0.001$} \\
\hline & Controls & 22 & $-24.5 \pm 4.4$ & \\
\hline & CMR+ & 23 & $-17.5 \pm 9.7$ & \\
\hline \multirow[t]{3}{*}{ EDSR (\%) } & CMR- & 38 & $77.2 \pm 22.4$ & \multirow[t]{3}{*}{0.003} \\
\hline & Controls & 22 & $79.7 \pm 25.6$ & \\
\hline & $\mathrm{CMR}^{+}$ & 23 & $59.2 \pm 17.2$ & \\
\hline
\end{tabular}

are missed by LGE $[19,20]$. Second, high energy turnover and representing the border zone of arterial blood supply make the subendocardium highly vulnerable to injury even at early stages of disease [21]. Consequently, the subendocardial layer is most susceptible to changes within the overall diseased myocardium.

This finding suggests that CMR-derived strain might have the potential to detect cardiac sarcoidosis at an earlier stage.

Noninvasive imaging, including detection of perfusion deficits using single photon emission computed tomography, presence of LGE, and impaired echocardiography-based GLS for a negative outcome, has been investigated previously [4, 22 - 24].

In the underlying study, 3 of 61 patients (5\%) showed an adverse cardiac event during follow-up. All three patients were CMR+ and presented with LGE. Corresponding to the results of Greulich et al. [23], LGE was predictive for adverse events in the current study collective. In addition to LGE, patients in the present study also showed associated increased EGEr and edema.

Due to the small number of negative outcomes in the underlying study, a cut-off value predictive for outcome could not be established. However, in agreement with Joyce et al. [4], who established an echo-based GLS cut-off value of $-17.3 \%$ for a negative outcome, all three patients with a negative outcome in the present study met the aforementioned criterion.

Although patients in this study were followed up for a longer period of time, fewer patients had a negative outcome compared to previously published studies employing similar endpoints and patient treatment $[23,25]$. However, this is possibly due to the small patient numbers, not allowing for true measurements of 
outcome, differences in disease severity and finally due to different definitions of outcome.

\section{Conclusion}

CMR-derived strain does not discriminate between CMR+ and CMR- patients with regular global left ventricular function. GLS is the only strain parameter that allows for the detection of left ventricular functional impairment in sarcoidosis patients with otherwise unsuspicious CMR. GLS is further reduced in patients with a negative outcome. Thus, GLS may serve as a marker for early cardiac involvement in sarcoidosis.

\section{Clinical relevance}

Early detection and monitoring of cardiac involvement in sarcoidosis patients is crucial in order to facilitate timely and adequate therapy and thus to counteract negative outcome. GLS has the potential to fulfill the above-mentioned requirements. However, further studies are needed to confirm the findings of this study.

$\begin{array}{ll}\text { LIST OF AB B REVIATIONS } \\ { }^{18} \text { FDG-PET } & \begin{array}{l}\text { 18fluoro-desoxy-glucose positron-emission } \\ \text { tomography }\end{array} \\ \text { AF } & \text { atrial fibrillation } \\ \text { AHA } & \text { American Heart Association } \\ \text { ARB } & \text { angiotensin receptor blockers } \\ \text { ASS } & \text { acetylsalicylic acid } \\ \text { AV } & \text { atrioventricular } \\ \text { BNP } & \text { brain natriuretic peptide } \\ \text { CCB } & \text { calcium channel blockers } \\ \text { CMR } & \text { cardiac magnetic resonance } \\ \text { DE } & \text { delayed enhancement } \\ \text { ECG } & \text { electrocardiographically / electrocardiogram } \\ \text { EDSR } & \text { early diastolic strain rate } \\ \text { EGEr } & \text { early gadolinium enhancement ratio } \\ \text { GLS } & \text { global longitudinal strain } \\ \text { HLA } & \text { horizontal long axis } \\ \text { IVST } & \text { interventricular septal thickness } \\ \text { JMHW } & \text { Japanese Ministry of Health and Welfare } \\ \text { LGE } & \text { late gadolinium enhancement } \\ \text { LV } & \text { left ventricular / left ventricle } \\ \text { LVEDV } & \text { left ventricular end-diastolic volume } \\ \text { LVEF } & \text { left ventricular ejection fraction } \\ \text { LVOT } & \text { left ventricular outflow tract } \\ \text { NT } & \text { N-terminal } \\ \text { PDSR } & \text { peak diastolic strain rate } \\ \text { PSECC } & \text { peak systolic circumferential strain } \\ \text { PSSR } & \text { peak systolic strain rate } \\ \text { RBBB } & \text { right bundle branch block } \\ \text { SA } & \text { short axis } \\ \text { Trop I } & \text { troponin I } \\ \text { VES } & \text { ventricular extrasystoles } \\ \text { VLA } & \text { vertical long axis } \\ & \end{array}$

\section{Conflict of Interest}

The authors declare that they have no conflict of interest.

\section{Acknowledgement}

Diese Arbeit ist Herrn Universitäts-Professor Hans H. Schild gewidmet, bei dem wir uns herzlich für die stete Unterstützung in allen klinischen und wissenschaftlichen Belangen bedanken möchten.

\section{References}

[1] Rybicki BA, Major M, Popovich J Jr et al. Racial differences in sarcoidosis incidence: a 5-year study in a health maintenance organization. Am J Epidemiol 1997; 145: 234-241

[2] Soejima K, Yada $\mathrm{H}$. The work-up and management of patients with apparent or subclinical cardiac sarcoidosis: with emphasis on the associated heart rhythm abnormalities. J Cardiovasc Electrophysiol 2009; 20: 578 - 583. doi:10.1111/j.1540-8167.2008.01417.x

[3] Kandolin R, Lehtonen J, Airaksinen J et al. Cardiac sarcoidosis: epidemiology, characteristics, and outcome over 25 years in a nationwide study. Circulation 2015; 131: 624-632. doi:10.1161/CIRCULATIONAHA.114.011522

[4] Joyce E, Ninaber MK, Katsanos S et al. Subclinical left ventricular dysfunction by echocardiographic speckle-tracking strain analysis relates to outcome in sarcoidosis. Eur J Heart Fail 2015; 17: 51 -62. doi:10.1002/ ejhf.205

[5] Nery PB, Beanlands RS, Nair GM et al. Atrioventricular block as the initial manifestation of cardiac sarcoidosis in middle-aged adults. J Cardiovasc Electrophysiol 2014; 25: 875-881. doi:10.1111/jce.12401

[6] Ohira H, Tsujino I, Ishimaru S et al. Myocardial imaging with 18F-fluoro2-deoxyglucose positron emission tomography and magnetic resonance imaging in sarcoidosis. Eur J Nucl Med Mol Imaging 2008; 35: 933 - 941. doi:10.1007/s00259-007-0650-8

[7] Friedrich MG, Strohm O, Schulz-Menger ] et al. Contrast media-enhanced magnetic resonance imaging visualizes myocardial changes in the course of viral myocarditis. Circulation 1998; 97: 1802-1809

[8] Kramer CM, Barkhausen J, Flamm SD et al. Standardized cardiovascular magnetic resonance (CMR) protocols 2013 update. J Cardiovasc Magn Reson 2013; 15: 91. doi:10.1186/1532-429X-15-91

[9] Moravsky G, Ofek E, Rakowski H et al. Myocardial fibrosis in hypertrophic cardiomyopathy: accurate reflection of histopathological findings by CMR. JACC Cardiovasc Imaging 2013; 6: 587 - 596. doi:10.1016/j. jcmg.2012.09.018

[10] Kuetting DL, Homsi R, Sprinkart AM et al. Quantitative assessment of systolic and diastolic function in patients with LGE negative systemic amyloidosis using CMR. Int J Cardiol 2017; 232: 336-341. doi:10.1016/ j.ijcard.2016.12.054

[11] Ennis DB, Epstein FH, Kellman P et al. Assessment of regional systolic and diastolic dysfunction in familial hypertrophic cardiomyopathy using MR tagging. Magn Reson Med 2003; 50: 638 -642. doi:10.1002/ mrm. 10543

[12] Mehta D, Lubitz SA, Frankel Z et al. Cardiac involvement in patients with sarcoidosis: diagnostic and prognostic value of outpatient testing. Chest 2008; 133: 1426 - 1435. doi:10.1378/chest.07-2784

[13] Cho GY, Marwick TH, Kim HS et al. Global 2-dimensional strain as a new prognosticator in patients with heart failure. J Am Coll Cardiol 2009; 54 : 618-624. doi:10.1016/j.jacc.2009.04.061

[14] Reant P, Mirabel M, Lloyd G et al. Global longitudinal strain is associated with heart failure outcomes in hypertrophic cardiomyopathy. Heart 2016; 102: 741 - 747. doi:10.1136/heartjnl-2015-308576 
[15] Mor-Avi V, Lang RM, Badano LP et al. Current and evolving echocardiographic techniques for the quantitative evaluation of cardiac mechanics: ASE/EAE consensus statement on methodology and indications endorsed by the Japanese Society of Echocardiography. Eur J Echocardiogr 2011; 12: 167-205. doi:10.1093/ejechocard/jer021

[16] Tigen K, Sunbul M, Karaahmet T et al. Early Detection of Bi-ventricular and Atrial Mechanical Dysfunction Using Two-Dimensional Speckle Tracking Echocardiography in Patients with Sarcoidosis. Lung 2015; 193 : 669-675. doi:10.1007/s00408-015-9748-0

[17] Orii M, Hirata K, Tanimoto T et al. Myocardial Damage Detected by TwoDimensional Speckle-Tracking Echocardiography in Patients with Extracardiac Sarcoidosis: Comparison with Magnetic Resonance Imaging. J Am Soc Echocardiogr 2015; 28: 683 -691. doi:10.1016/j. echo.2015.02.018

[18] Murtagh G, Laffin LJ, Patel KV et al. Improved detection of myocardia damage in sarcoidosis using longitudinal strain in patients with preserved left ventricular ejection fraction. Echocardiography 2016; 33 1344-1352. doi:10.1111/echo.13281

[19] Puntmann VO, Voigt T, Chen Z et al. Native T1 mapping in differentiation of normal myocardium from diffuse disease in hypertrophic and dilated cardiomyopathy. JACC Cardiovasc Imaging 2013; 6: 475-484. doi:10.1016/j.jcmg.2012.08.019
[20] Tavora F, Cresswell N, Li L et al. Comparison of necropsy findings in patients with sarcoidosis dying suddenly from cardiac sarcoidosis versus dying suddenly from other causes. Am J Cardiol 2009; 104: 571 - 577. doi:10.1016/j.amjcard.2009.03.068

[21] Stanton T, Marwick TH. Assessment of subendocardial structure and function. JACC Cardiovasc Imaging 2010; 3: 867 -875. doi:10.1016/j. jcmg.2010.05.011

[22] Eguchi M, Tsuchihashi K, Hotta D et al. Technetium-99m sestamibi/ tetrofosmin myocardial perfusion scanning in cardiac and noncardiac sarcoidosis. Cardiology 2000; 94: 193 -199. doi:47316

[23] Greulich S, Deluigi CC, Gloekler S et al. CMR imaging predicts death and other adverse events in suspected cardiac sarcoidosis. JACC Cardiovasc Imaging 2013; 6: 501-511. doi:10.1016/j.jcmg.2012.10.021

[24] Patel MR, Cawley PJ, Heitner JF et al. Detection of myocardial damage in patients with sarcoidosis. Circulation 2009; 120: 1969-1977. doi:10.1161/CIRCULATIONAHA.109.851352

[25] Nadel J, Lancefield T, Voskoboinik A et al. Late gadolinium enhancement identified with cardiac magnetic resonance imaging in sarcoidosis patients is associated with long-term ventricular arrhythmia and sudden cardiac death. Eur Heart ] Cardiovasc Imaging 2015; 16: 634-641. doi:10.1093/ehjci/jeu294 